\title{
Blood Viscosity in Subjects With Type 2 Diabetes Mellitus: Roles of Hyperglycemia and Elevated Plasma Fibrinogen
}

\section{OPEN ACCESS}

Edited by:

Gregory Barshtein,

Hebrew University of Jerusalem, Israe

Reviewed by:

Herbert J. Meiselman

Independent Researcher,

Los Angeles, United States

Giovanna Tomaiuolo,

University of Naples Federico II, Italy

Pedro Cabrales,

University of California, San Diego,

United States

*Correspondence:

Jin Qian

jqian@zju.edu.cn

$\mathrm{Li} \mathrm{Li}$

lilyningbo@163.com

Xuejin $\mathrm{Li}$

xuejin_li@zju.edu.cn

tThese authors have contributed equally to this work

Specialty section:

This article was submitted to

Red Blood Cell Physiology,

a section of the journal

Frontiers in Physiology

Received: 02 December 2021

Accepted: 20 January 2022

Published: 25 February 2022

Citation:

Sun J, Han K, Xu M, Li L, Qian J, Li L and LiX (2022) Blood Viscosity in

Subjects With Type 2 Diabetes Mellitus: Roles of Hyperglycemia and Elevated Plasma Fibrinogen.

Front. Physiol. 13:827428

doi: 10.3389/fphys.2022.827428

\author{
Jiehui Sun ${ }^{1 \dagger}$, Keqin $\mathrm{Han}^{2 \dagger}$, Miao Xu ${ }^{1}$, Lujuan $\mathrm{Li}^{2}$, Jin Qian ${ }^{2 *}, \mathrm{Li} \mathrm{Li}^{1 *}$ and Xuejin $\mathrm{Li}^{2 *}$ \\ ${ }^{1}$ Department of Endocrinology and Metabolism, Ningbo First Hospital, Ningbo, China, ${ }^{2}$ Department of Engineering \\ Mechanics, Zhejiang University, Hangzhou, China
}

The viscosity of blood is an indicator in the understanding and treatment of disease. An elevated blood viscosity has been demonstrated in patients with Type 2 Diabetes Mellitus (T2DM), which might represent a risk factor for cardiovascular complications. However, the roles of glycated hemoglobin $\left(\mathrm{HbA}_{1 \mathrm{c}}\right)$ and plasma fibrinogen levels on the elevated blood viscosity in subjects with T2DM at different chronic glycemic conditions are still not clear. Here, we evaluate the relationship between the blood viscosity and $\mathrm{HbA}_{1 \mathrm{c}}$ as well as plasma fibrinogen levels in patients with T2DM. The experimental data show that the mean values of the T2DM blood viscosity are higher in groups with higher $\mathrm{HbA}_{1 c}$ levels, but the correlation between the T2DM blood viscosity and the $\mathrm{HbA}_{\mathrm{lc}}$ level is not obvious. Instead, when we investigate the influence of plasma fibrinogen level on the blood viscosity in T2DM subjects, we find that the T2DM blood viscosity is significantly and positively correlated with the plasma fibrinogen level. Further, to probe the combined effects of multiple factors (including the $\mathrm{HbA}_{1 \mathrm{c}}$ and plasma fibrinogen levels) on the altered blood viscosity in T2DM, we regroup the experimental data based on the T2DM blood viscosity values at both the low and high shear rates, and our results suggest that the influence of the elevated $\mathrm{HbA}_{1 c}$ level on blood viscosity is quite limited, although it is an important indicator of glycemic control in T2DM patients. Instead, the elevated blood hematocrit, the enhanced red blood cell (RBC) aggregation induced by the increased plasma fibrinogen level, and the reduced RBC deformation play key roles in the determination of blood viscosity in T2DM. Together, these experimental results are helpful in identifying the key determinants for the altered T2DM blood viscosity, which can be used in future studies of the hemorheological disturbances of T2DM patients.

Keywords: red blood cell, blood flow, blood viscosity, diabetes mellilus, RBC aggregation, RBC deformation

\section{INTRODUCTION}

Blood is a non-Newtonian fluid that delivers necessary substances-such as nutrients and oxygento living cells and removes metabolic waste products (Popel and Johnson, 2005; Secomb, 2017). In vertebrates, it is composed primarily of blood cells suspended in blood plasma. In microcirculation, blood cells are subjected to intense mechanical stimulation from both blood flow and vessel walls; hence, their mechanical and rheological properties are important to their effectiveness in 
performing their biological functions (Yedgar et al., 2002; Baskurt and Meiselman, 2003; Yao et al., 2003; Chen et al., 2007; Fedosov et al., 2014a; Barshtein et al., 2016, 2018, 2021; Sohrabi et al., 2017; Tan et al., 2018; Xiao et al., 2020; Chien et al., 2021). A change in blood rheological property is usually linked to blood disorders; therefore, understanding the flow dynamics and rheological properties of blood allows us to know how blood viscosity impacts cognitive functions, and provides direction for therapeutic interventions (Chien et al., 1970a; Ballas et al., 1989; Fedosov et al., 2014b; Du et al., 2015; Barshtein et al., 2017; Perakakis et al., 2018). Blood viscosity has been extensively investigated and now it is generally believed that five factors, namely blood hematocrit (Hct), red blood cell (RBC) deformability, RBC aggregation, plasma viscosity, and temperature, primarily determine the rheological behavior of blood (Chien et al., 1966, 1967, 1970b; Berger and King, 1980; Barshtein et al., 2007; Fedosov et al., 2011b; Lei and Karniadakis, 2013). In blood flow, the RBC aggregation is attributed to the macromolecules such as plasma protein fibrinogen and synthetic polymer dextran, which promote the formation of RBC aggregates in the form of rouleaux (Brust et al., 2014; KrügerGenge et al., 2019) and eventually lead to an increased blood viscosity (Matsuda and Murakami, 1976; Tomaiuolo et al., 2016). The deformability of the RBCs, or the ability of the RBCs to deform their shape under applied stress, plays an important role in the main function of the RBCs. In pathological conditions, these alterations could result in impaired blood flow and other aspects of vascular complications. For example, the malariainfected RBCs show progressing alteration of their mechanical and adhesive properties as the parasite develops (Zhang et al., 2015; Dearnley et al., 2016; Banas et al., 2021). These changes greatly affect rheological properties of malaria-infected RBCs and lead to obstructions of small capillaries (Shelby et al., 2003; Fedosov et al., 2011a).

Diabetes mellitus (DM), the fastest growing chronic disease worldwide, is a metabolic disease characterized by persistently elevated glucose levels in the blood (Mathers and Loncar, 2006; Deng et al., 2021). Generally, the most widely used indicators of glycemic control for diabetic patients are the blood glucose level and the glycated haemoglobin $\left(\mathrm{HbA}_{1 \mathrm{c}}\right)$ level. Compared to the former, the $\mathrm{HbA}_{1 \mathrm{c}}$ level has little biological variability and reflects the average glucose concentration over the preceding 8-12 weeks (Sacks, 2011). In addition, the glycated serum protein (GSP) level, which is the amount of glucose attached to total serum proteins, offers an alternative approach for assessing glycemia in instances where $\mathrm{HbA}_{1 \mathrm{c}}$ may be of limited value such as pregnancy and reduced RBC lifespan. Type 2 diabetes mellitus (T2DM), the most common type of DM, is characterized by relative insulin deficiency caused by pancreatic cell dysfunction and insulin resistance in target organs (Chatterjee et al., 2017). Individuals with T2DM usually suffer from elevated level of $\mathrm{HbA}_{1 \mathrm{c}}$, which has been identified as an emerging risk factor for developing microvascular and macrovascular complications, (Fowler, 2008) such as diabetic retinopathy, (Brazionis et al., 2008; Cho, 2011; Li et al., 2020) diabetic nephropathy, (Young et al., 1993; Davies et al., 2006; Jeganathan et al., 2008) diabetic peripheral and autonomic neuropathy (Yang et al., 2020).
The viscosity of blood is a direct measure of the resistance of blood to flow through blood vessel. According to Poiseuille's law, the rate of blood flow through a small blood vessel can be calculated from the following algebraic equation: (Phillips et al., 2008).

$$
Q=\left(\pi \times r^{4} \times \Delta P\right) /\left(8 \times \eta_{\mathrm{BV}} \times L\right)
$$

where $r$ and $L$ are the radius and length of the blood vessel, $\Delta P$ is the difference in blood pressure between the ends of the blood vessel, and $\eta_{\mathrm{BV}}$ is the viscosity of blood. Holding other parameters constant, higher blood viscosity should retard blood flow through blood vessels, which would contribute to insulin resistance and T2DM and eventually lead to diabetic microangiopathy and other circulation problems (Fowler, 2008).

It is generally accepted that the blood viscosity is higher in T2DM patients than in non-diabetic control subjects (Skovborg et al., 1966; Turczynski et al., 2003; Tamariz et al., 2008). Although the reasons for the elevation in blood viscosity are still under investigation, it is believed that the osmotic diuresis, consequence of high $\mathrm{HbA}_{1 \mathrm{c}}$ level, could contribute to increase blood hematocrit and reduce plasma volume (Agrawal et al., 2016). It has also been suggested that the reduced $\mathrm{RBC}$ deformability, increased RBC and platelet aggregation, and enhanced platelet adhesion to activated endothelium would contribute to blood hyperviscosity (Schmid-Schönbein and Volger, 1976; McMillan, 1983; Beamer et al., 1997; Cho et al., 2008; Cloutier et al., 2008; Chang et al., 2017, 2018; Li et al., 2018). For example, Turczynski et al. (2003) showed that the T2DM blood viscosity is positively correlated with retinopathy severity, which is attributed to the decreased RBC deformability. Skovborg et al. (1966) revealed that the blood viscosity of diabetic subjects is around 20\% higher than that of controls. Ercan et al. (2002) suggested that the elevated plasma cholesterol contributes to increased blood viscosity by an additional effect of hyperglycemia in T2DM patients. Yazdani et al. (2021) integrated blood cell mechanics, platelet adhesive dynamics, and coagulation cascade to model the thrombus formation in diabetic blood. They showed that both the pathological alterations in the biomechanical properties of blood cells and changes in the amount of coagulation factors would contribute to the enhanced platelet adhesion and aggregation in diabetic blood. In addition, it shows that the aggregation of the RBCs is far commoner among the T2DM patients than that among the non-diabetes (MacRury et al., 1993; Babu and Singh, 2004; Deng et al., 2020). It is recognized that the plasma fibrinogen level is one of the dominant factors promoting the formation of RBC aggregates (rouleaux), which could cause an elevated blood viscosity under low shear rate (Krüger-Genge et al., 2019; Deng et al., 2020).

The viscosity of blood has long been used as an indicator in the understanding and treatment of disease (Fedosov et al., 2011a). Previous studies have examined the relationship between blood viscosity, Hct, plasma viscosity, $\mathrm{RBC}$ deformability, and platelet adhesion in T2DM patients. However, all studies so far have investigated the effects of just a few of the aforementioned factors in hemorheology and vascular occlusion in certain glucose conditions and for certain time. The roles of hyperglycemia and 
elevated plasma fibrinogen level on the altered blood viscosity at different chronic glycemic conditions is not completely clear. In this article, we evaluate the influences of both the $\mathrm{HbA}_{1 \mathrm{c}}$ and plasma fibrinogen levels on the T2DM blood viscosity to clarify whether the alterations in blood viscosity are appreciable in these T2DM subjects.

\section{MATERIALS AND METHODS}

\subsection{Selection of T2DM Blood Samples}

In this study, blood samples from 318 patients (199 male and 119 female, mean age $56.80 \pm 12.92$ ) with T2DM were collected during fasting glucose tests, following institutional review board (IRB) approvals from the Ningbo City First Hospital. In the fasting glucose tests, the patients were asked to fast for overnight before morning blood collection to avoid the influence of postprandial lipid increase on hemorheological characteristics (Stamos and Rosenson, 1999). To investigate the effect of the $\mathrm{HbA}_{1 \mathrm{c}}$ level on the hemorheological properties of T2DM blood, these blood samples were collected in a wide range of the $\mathrm{HbA}_{1 \mathrm{c}}$ levels. All blood samples were collected into vacuum tubes ( 5 $\mathrm{ml})$ containing Heparin Lithium salt $(75 \mathrm{IU} / \mathrm{ml})$ anticoagulant and stored at $4{ }^{\circ} \mathrm{C}$ for in vitro testing within $4 \mathrm{~h}$ from blood withdrawal. The levels of $\mathrm{HbA}_{1 \mathrm{c}}$ and GSP, which are the two key parameters for the assessment of long-term glucose control in diabetes, were measured in all 318 subjects. The level of plasma fibrinogen $\left(c_{\mathrm{FN}}\right)$ and other biochemical and hematologic parameters were also measured using standard methods. The values of Hct were measured as the fraction of the RBCs suspended in plasma following blood centrifugation.

The whole blood viscosity was measured at native Hct using a cone-plate viscometer (SA-6600, Beijing Succeeder Technology Inc, China). The angle between the surface of the cone and the plate was of the order of $1^{\circ}$, where the shear rate was regulated by rotor speed during measurement. Viscosity measurements were completed within $4 \mathrm{~h}$ of sample collection by the following procedures: (1) the rheometer was initialized to desired test condition (force and gap) and the turntable and dosing pin were restored to zero; (2) the temperature of the blood rheometer was pre-heated for $30 \mathrm{~min}$ to $37^{\circ} \mathrm{C}$; (3) the whole blood was added to the tube with a dosing needle for dilution (100:1) and mixed well; (4) the tube was placed on the pre-heated plate $\left(37^{\circ} \mathrm{C}\right)$; (5) the whole mensuration was then automatically controlled by the computer in a rapid, pointwise, prompt, steady-state method, and the two-dimensional curve for the blood viscosity and shear rate was traced in real-time. The test time for whole blood was within 30 s/sample.

It is known that the blood is a non-Newtonian fluid, which means that its viscosity depends on the shear rate. At low shear rates, the aggregation of RBCs induces a sharp increase in blood viscosity. At high shear rates, the blood becomes less viscous as the RBCs disaggregate, deform and align in the direction of flow. According to previous experimental and computational studies, (Skalak et al., 1981; Fedosov et al., 2011b) the blood viscosity decreased only $10 \%$ when the shear rate rises from 200.0 to $1000.0 \mathrm{~s}^{-1}$. In our opinion, the blood viscosity measured over a range of shear rates in 200.0 to $1.0 \mathrm{~s}^{-1}$ can reflect the nonNewtonian behavior of T2DM blood. Hence, in this study, the blood viscosity curves were plotted as a function of shear rate ranging from 200.0 to $1.0 \mathrm{~s}^{-1}$ for whole blood samples. Then, the values of whole blood viscosity $\left(\eta_{\mathrm{BV}}\right)$ were chosen and analyzed at three certain shear rates (i.e., $\dot{\gamma}=1.0,50.0$, and $200.0 \mathrm{~s}^{-1}$ ). The plasma viscosity $\left(\eta_{\mathrm{PV}}\right)$ was measured with a capillary viscometer.

It is generally believed that surface tension plays an important role in the way liquids behave. In general, it is the property of a liquid's surface, which is caused by unbalanced forces on surface molecules that pull toward the main part of the liquid. The blood viscosity is a measure of the resistance of a liquid that is being deformed or moved. As it can be noticed that the origin of the two properties is not directly related to one another. Therefore, there is no conclusive correlation between the surface tension and viscosity (Wesołowski and Młynarczak, 2019). Hence, we did not investigate the effect of blood surface tension in the measurement of blood viscosity at low shear rates.

The ability of the RBCs to deform their shape under applied shear stress are represented by RBC deformability index (Di) or $\mathrm{RBC}$ rigidity index (Ri). In past decades, advances in experimental techniques (such as erythrocyte filtration, laser diffraction ellipsometry, micropipette aspiration) have allowed to measure the RBC Di and RBC Ri parameters averaged over a large number of RBCs in blood sample (Dintenfass, 1985; Nash and Meiselman, 1985; Mokken et al., 1992; Kameneva et al., 1999; Spengler et al., 2011). As suggested by previous experimental studies on the measurements of rheological characteristics of the blood, (Spengler et al., 2011) the RBC Ri parameter (i.e., the inverse of RBC deformability) is evaluated according to the following formula,

$$
\mathrm{Ri}=\frac{\eta_{\mathrm{BV}, 200.0} / \eta_{\mathrm{PV}}-1.0}{\mathrm{Hct}}
$$

where $\eta_{\mathrm{BV}, 200.0}$ is the whole blood viscosity at shear rate of $\dot{\gamma}=$ $200.0 \mathrm{~s}^{-1}$. Apparently, an increase in the RBC Ri would lead to a reduction in the $\mathrm{RBC}$ deformability. Additionally, the RBCs in whole blood aggregate into rouleaux at low shear rates, leading to an obvious increase in blood viscosity, whereas the large RBC aggregates can break down into small structures or isolated RBCs under high shear rates (Fedosov et al., 2011b). Herein, the RBC aggregation index (Ai) is estimated by the ratio of low shear viscosity and high shear viscosity based on the following formula, (Bull et al., 1986).

$$
\mathrm{Ai}=\frac{\eta_{\mathrm{BV}, 1.0}}{\eta_{\mathrm{BV}, 200.0}}
$$

where $\eta_{\mathrm{BV}, 1.0}$ is whole blood viscosity at shear rates of $\dot{\gamma}=1.0 \mathrm{~s}^{-1}$.

\subsection{Statistical Analysis}

All statistical data analyses were performed using SPSS 25.0 for Windows. One-way Analysis of Variance (ANOVA) and Least Significant Difference (LSD) post-hoc test were used to analyze the difference in studied variables between groups with different $\mathrm{HbA}_{1 \mathrm{c}}$ and plasma fibrinogen levels. Pearson's correlation analysis was used to test the statistical relationship 
TABLE 1 | Selected biochemical, hematologic and hemorheological characteristics of the T2DM blood subjects by tertile of the $\mathrm{HbA}_{1 \mathrm{c}}$ level.

\begin{tabular}{lcccc}
\hline \multirow{2}{*}{ Item } & \multicolumn{3}{c}{ Subjects } & P \\
\cline { 2 - 3 } & Group A & Group B & Group C & \\
\cline { 2 - 4 } Sex(M/F) & $40 / 18$ & $96 / 71$ & $63 / 30$ & - \\
Age & $56.48 \pm 12.92$ & $58.82 \pm 12.33$ & $56.42 \pm 13.87$ & 0.260 \\
Hct (\%) & $42.03 \pm 4.23$ & $42.86 \pm 4.24$ & $42.33 \pm 4.54$ & 0.381 \\
MCV (fL) & $92.07 \pm 4.84$ & $91.44 \pm 5.25$ & $89.74 \pm 3.57$ & 0.005 \\
$N_{\mathrm{RBC}}\left(10^{6} / \mu \mathrm{L}\right)$ & $4.58 \pm 0.54$ & $4.71 \pm 0.58$ & $4.73 \pm 0.55$ & 0.254 \\
GSP $(\%)$ & $2.00 \pm 0.34$ & $2.74 \pm 0.63^{*}$ & $3.92 \pm 0.832^{* \$}$ & $<0.001$ \\
$C_{\mathrm{FN}}(\mathrm{mg} / \mathrm{dL})$ & $2.91 \pm 0.43$ & $3.07 \pm 0.62$ & $2.92 \pm 0.65$ & 0.079 \\
$\eta_{\mathrm{PV}}(\mathrm{mPa} \cdot \mathrm{s})$ & $1.38 \pm 0.09$ & $1.41 \pm 0.09$ & $1.41 \pm 0.09$ & 0.029 \\
$\eta_{\mathrm{BV}, 1.0}(\mathrm{mPa} \cdot \mathrm{s})$ & $16.70 \pm 3.26$ & $17.06 \pm 2.82$ & $16.98 \pm 3.08$ & 0.739 \\
$\eta_{\mathrm{BV}, 50.0}(\mathrm{mPa} \cdot \mathrm{s})$ & $4.45 \pm 0.58$ & $4.61 \pm 0.60$ & $4.57 \pm 0.67$ & 0.258 \\
$\eta_{\mathrm{BV}, 200.0}(\mathrm{mPa} \cdot \mathrm{s})$ & $3.80 \pm 0.48$ & $3.91 \pm 0.50$ & $3.87 \pm 0.56$ & 0.395 \\
$\mathrm{Ai}$ & $4.38 \pm 0.63$ & $4.37 \pm 0.57$ & $4.40 \pm 0.50$ & 0.917 \\
$\mathrm{Ri}$ & $3.92 \pm 0.61$ & $3.98 \pm 0.58$ & $3.92 \pm 0.67$ & 0.687 \\
\hline
\end{tabular}

Group A: $H b A_{1 c}<6.5 \%$; Group B: $6.5 \% \leq H b A_{1 c}<10.0 \%$; Group C: $H b A_{1 c} \geq 10.0 \%$. Hct, hematocrit; $M C V$, mean cell volume; $N_{R B C}, R B C$ count; GSP, glycated serum protein; $C_{F N}$, plasma fibrinogen level; $\eta_{P V}$, plasma viscosity; $\eta_{B V, 1.0}, \eta_{B V, 50.0}, \eta_{B V, 200.0}$ are whole blood viscosity at shear rates $\dot{\gamma}=1.0 \mathrm{~s}^{-1}, 50.0 \mathrm{~s}^{-1}$ and $200.0 \mathrm{~s}^{-1}$, respectively; $A i, R B C$ aggregation index; Ri, RBC rigidity index. ${ }^{*}, P<0.05$, vs. Group $A$; ${ }^{\$}, P<0.05$, vs. Group $B$.

between two continuous variables. A simple correlation analysis was performed to evaluate the independent association of clinical and biochemical variables with the $\mathrm{HbA}_{1 \mathrm{c}}$ and plasma fibrinogen levels. In this study, the significance level was set as 0.05 . If the $P$-value is lower than the significance level, it means that the relationship between two or more variables are statistically significant. Additionally, the $R$-value and confidence interval (with the confidence level of 95\%) were also included in the Pearson's correlation analysis.

\section{RESULTS AND DISCUSSION}

\subsection{Effect of Glycated Hemoglobin Level on T2DM Blood Rheology}

All T2DM blood subjects were divided into three groups according to their $\mathrm{HbA}_{1 \mathrm{c}}$ levels: Group A (subjects with good glycemic control, $\mathrm{HbA}_{1 \mathrm{c}}<6.5 \%$ ), Group $\mathrm{B}$ (subjects with poor glycemic control, $6.5 \% \leq \mathrm{HbA}_{1 \mathrm{c}}<10.0 \%$ ), and Group C (subjects with the worst glycemic control, $\mathrm{HbA}_{1 \mathrm{c}} \geq 10.0 \%$ ). Selected biochemical, hematologic and hemorheological parameters in these three different groups are listed in Table 1. It shows that the levels of GSP are significantly higher in the T2DM blood subjects with higher $\mathrm{HbA}_{1 \mathrm{c}}$ levels (Groups $\mathrm{B}$ and $\mathrm{C}$ ) compared to that in the T2DM blood subjects with lower $\mathrm{HbA}_{1 \mathrm{c}}$ level (Group A). The values of Hct are similar in these three different groups but the $\mathrm{RBC}$ counts $\left(N_{\mathrm{RBC}}\right)$ are higher in Groups B and C compared to that in Group A, resulting in lower values of MCV in Groups B and $\mathrm{C}$ based on the following equation,

$$
\operatorname{MCV}(\mathrm{fL})=\frac{\mathrm{Hct} \%}{N_{\mathrm{RBC}} \times 10^{6} / \mu \mathrm{L}} \times 10
$$

The value of plasma fibrinogen level $c_{\mathrm{FN}}$ is slightly higher in Group B compared to those in other two groups; however, there are no significant differences among these three different groups $(P=0.079)$. Additionally, the values of RBC Ai and Ri are almost the same among the three groups, which indicates that these two factors remain unaffected by the changes in the $\mathrm{HbA}_{1 \mathrm{c}}$ level.

With regards to the rheological properties of T2DM blood, it shows that the T2DM blood subjects with higher $\mathrm{HbA}_{1 \mathrm{c}}$ levels (Groups B and C) have little bit higher values of plasma viscosity $\eta_{\mathrm{PV}}$, compared to that in the T2DM blood subjects with lower $\mathrm{HbA}_{1 \mathrm{c}}$ level (Group A). The values of blood viscosity $\eta_{\mathrm{BV}}$ at all three selected shear rates $\left(\dot{\gamma}=1.0,50.0\right.$, and $\left.200.0 \mathrm{~s}^{-1}\right)$ are also higher in Groups B and C compared to those in Group A; however, there are no statistically significant differences in the mean $\eta_{\mathrm{BV}}$ values among the three groups $(P \geq 0.258)$, indicating that the $\mathrm{HbA}_{1 \mathrm{c}}$ level did not seem to have important effect on the blood viscosity.

Next, we investigate the functional dependencies of the GSP level, plasma viscosity $\eta_{\mathrm{PV}}$, low-shear-rate blood viscosity $\eta_{\mathrm{BV}, \text { low }}\left(\dot{\gamma}=1.0 \mathrm{~s}^{-1}\right)$ and high-shear-rate blood viscosity $\eta_{\mathrm{BV} \text {,high }}$ $\left(\dot{\gamma}=200.0 \mathrm{~s}^{-1}\right)$ on the $\mathrm{HbA}_{1 \mathrm{c}}$ level, see Figure 1. It shows that the GSP level is significantly and positively correlated with the $\mathrm{HbA}_{1 \mathrm{c}}$ level (Figure 1A). This agrees with several reported studies (Lapolla et al., 1988; Bahceci et al., 2005). With regards to the rheological properties of T2DM blood, the measurements of plasma viscosity (Figure 1B), low-shearrate blood viscosity (Figure 1C), and high-shear-rate blood viscosity (Figure 1D) show large fluctuations with the $\mathrm{HbA}_{1 \mathrm{c}}$ level. However, neither the plasma viscosity (Figure 1B) nor the blood viscosity (Figures 1C,D) shows obvious correlation with the $\mathrm{HbA}_{1 \mathrm{c}}$ level. These results further demonstrate that the contribution of the $\mathrm{HbA}_{1 \mathrm{c}}$ level to the blood viscosity seems quite limited, at least in apparently T2DM blood subjects and at the shear rates used in the present study.

\subsection{Effect of Plasma Fibrinogen Level on T2DM Blood Rheology}

In T2DM patients, the RBC aggregation induced by the plasma fibrinogen level is a key determinant of the non-Newtonian flow behavior of human blood, especially at low shear rates, which has been suggested as a possible contributing factor for the occurrence and progression of diabetic microangiopathy (Krüger-Genge et al., 2019; Deng et al., 2020; Li et al., 2020). Next, we investigate the influence of plasma fibrinogen level on the blood viscosity in T2DM.

All T2DM blood subjects are divided into three groups according to their plasma fibrinogen levels $c_{\mathrm{FN}}$ : Group A $\left(c_{\mathrm{FN}}\right.$ $<2.5 \mathrm{mg} / \mathrm{dL})$, Group B $\left(2.5 \mathrm{mg} / \mathrm{dL} \leq \mathrm{c}_{\mathrm{FN}}<3.5 \mathrm{mg} / \mathrm{dL}\right)$, and Group $\mathrm{C}\left(c_{\mathrm{FN}} \geq 3.5 \mathrm{mg} / \mathrm{dL}\right)$. Selected biochemical, hematologic and hemorheological parameters in these blood subjects are listed in Table 2. It shows that there are no statistically significant differences in the mean values of Hct, MCV, RBC count, and $\mathrm{HbA}_{1 \mathrm{c}}$ level among the three groups $(P \geq 0.168)$. Additionally, it shows that the RBC Ri remains unaffected by the changes in plasma fibrinogen level $c_{\mathrm{FN}}$. However, our results indeed show a closer correlation between the RBC Ai and the plasma 

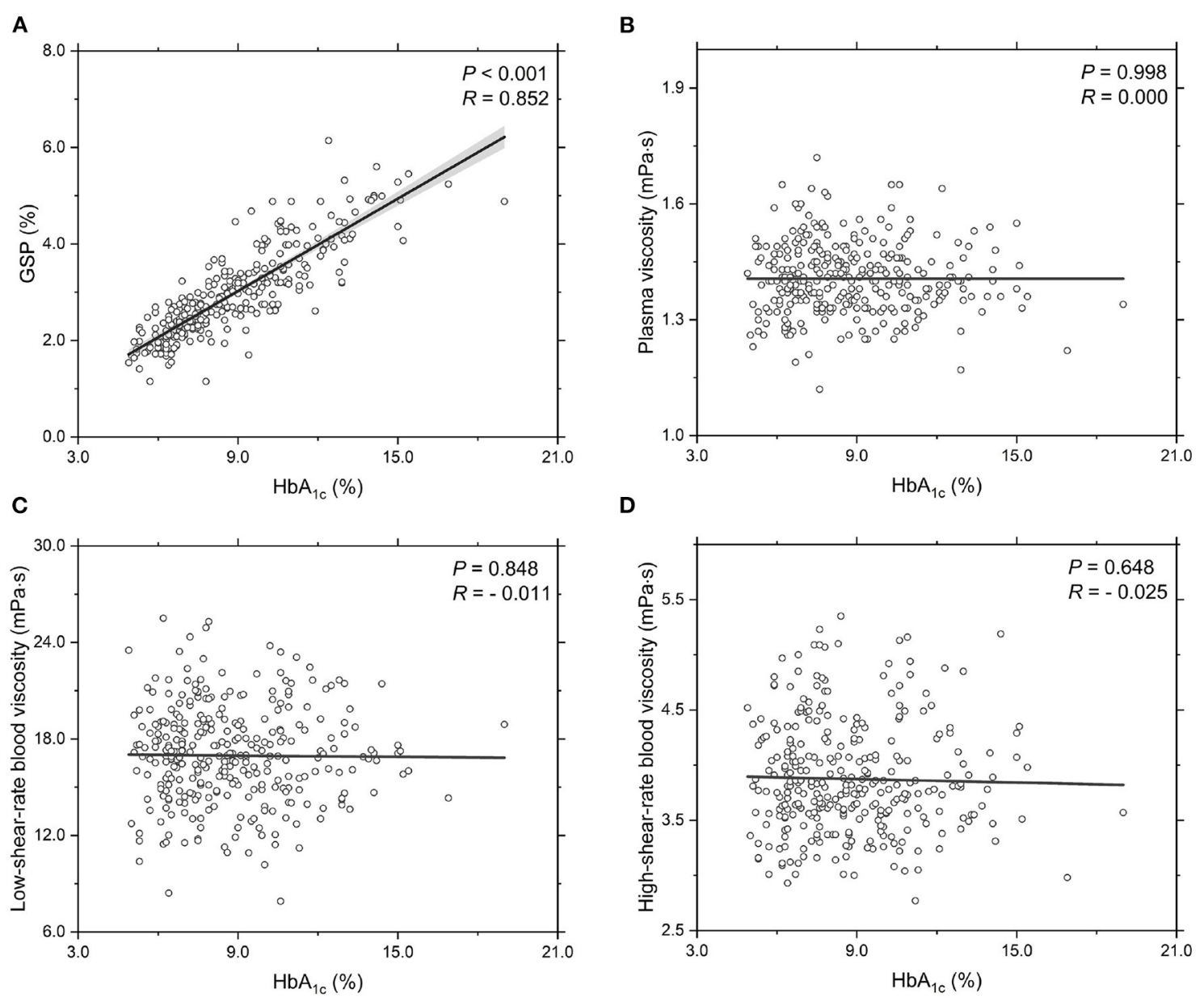

FIGURE 1 | Functional dependencies of (A) GSP, (B) plasma viscosity $\eta_{\mathrm{PV}}$, (C) low-shear-rate blood viscosity $\eta_{\mathrm{BV}, \text { low }}$ at $\dot{\gamma}=1.0 \mathrm{~s}^{-1}$, and (D) high-shear-rate blood viscosity $\eta_{\mathrm{BV} V \text {,high }}$ at $\dot{\gamma}=200.0 \mathrm{~s}^{-1}$ with respect to $\mathrm{HbA}_{1 \mathrm{C}}$ level. Shadow region represents $95 \%$ confidence interval.

fibrinogen level $c_{\mathrm{FN}}(P=0.035)$, namely, the values of RBC $\mathrm{Ai}$ are higher in Groups B and C compared to that in Group A. These results confirm that the plasma fibrinogen mainly affects the RBC aggregation characteristics. With regards to the rheological properties of T2DM blood, it shows that the T2DM blood subjects with higher $c_{\mathrm{FN}}$ (Groups $\mathrm{B}$ and $\mathrm{C}$ ) have higher values of plasma viscosity $\eta_{\mathrm{PV}}$ and blood viscosity $\eta_{\mathrm{BV}}$ at all three shear rates $\left(\dot{\gamma}=1.0,50.0\right.$, and $\left.200.0 \mathrm{~s}^{-1}\right)$, compared to those blood subjects with lower $c_{\mathrm{FN}}$ (Group A). For example, the values of low-shear-rate blood viscosity $\eta_{\mathrm{BV}, \text { low }}$ at $\dot{\gamma}=1.0 \mathrm{~s}^{-1}$ in Groups B and $\mathrm{C}$ were around 7.6 and $8.7 \%$ higher than that in Group A.

To further probe the rheological behavior of T2DM blood, we investigate the functional dependencies of plasma viscosity $\eta_{\mathrm{PV}}$ and low-shear-rate blood viscosity $\eta_{\mathrm{BV} \text {,low }}$ on the plasma fibrinogen level $c_{\mathrm{FN}}$, see Figure 2. It shows that the plasma viscosity $\eta_{\mathrm{PV}}$ positively correlated with the plasma fibrinogen level $c_{\mathrm{FN}}$ (Figure 2A), which agrees with previous experimental studies that the plasma viscosity increases with plasma fibrinogen level (Brunner, 2007). Regarding the dependence of low-shearrate blood viscosity on plasma fibrinogen level, the values of $\eta_{\mathrm{BV}, \text { low }}$ show a positive correlation with plasma fibrinogen level (Figure 2B), which is mainly attributed to the enhanced fibrinogen-induced RBC aggregation and the increased plasma viscosity. This result is also consistent with previous experimental study that the blood viscosity elevation is associated with the increased plasma fibrinogen level (Matsuda and Murakami, 1976). Compared to the experimental results presented in Subsection 3.1, we conclude that an increased plasma fibrinogen level is more important to the elevated blood viscosity than the increase in $\mathrm{HbA}_{1 \mathrm{c}}$ level.

\subsection{Multi-Factor Analysis in Altered T2DM Blood Rheology}

There are several different factors affecting blood viscosity, especially under pathological conditions. Hence, an increased blood viscosity may be the reason why the other biochemical, hematologic and metabolic factors are important, and provides the underlying mechanism through which these other factors convey the pre-inflammatory insult to blood vessel walls (Sloop, 1996). An alternative method of analysis is to group patients 
into different categories by their blood viscosity levels (Ciuffetti et al., 2005). To probe the combined effects of multiple factors in altered blood rheology in T2DM, we consider to regroup the experimental data based on the values of blood viscosity at both the low and high shear rates. At low shear rate $\left(\dot{\gamma}=1.0 \mathrm{~s}^{-1}\right)$, all T2DM blood subjects are divided into three groups according to their blood viscosity values: Group $\mathrm{A}\left(\eta_{\mathrm{BV}, 1.0}<15.0 \mathrm{mPa} \cdot \mathrm{s}\right)$, Group B $\left(15.0 \mathrm{mPa} \cdot \mathrm{s} \leq \eta_{\mathrm{BV}, 1.0}<19.0 \mathrm{mPa} \cdot \mathrm{s}\right)$, and Group C $\left(\eta_{\mathrm{BV}, 1.0} \geq 19.0 \mathrm{mPa} \cdot \mathrm{s}\right)$. Selected biochemical, hematologic and hemorheological parameters in these three blood groups are listed in Table 3. It shows that the Hct levels and RBC counts $\left(N_{\mathrm{RBC}}\right)$ appear opposite trends with the age from Group A to

TABLE 2 | Selected biochemical, hematologic and hemorheological characteristics of the T2DM blood subjects by tertile of the plasma fibrinogen level $c_{\mathrm{FN}}$.

\begin{tabular}{|c|c|c|c|c|}
\hline \multirow{2}{*}{ Item } & \multicolumn{3}{|c|}{ Subjects } & \multirow{2}{*}{$P$} \\
\hline & Group A & Group B & Group C & \\
\hline $\operatorname{Sex}(M / F)$ & $42 / 11$ & $127 / 95$ & $30 / 13$ & - \\
\hline Age & $55.11 \pm 13.14$ & $57.93 \pm 12.83$ & $59.67 \pm 12.94$ & 0.202 \\
\hline Hct (\%) & $42.22 \pm 4.26$ & $42.45 \pm 4.34$ & $43.54 \pm 4.31$ & 0.262 \\
\hline MCV (fL) & $90.78 \pm 4.31$ & $91.26 \pm 4.78$ & $90.37 \pm 5.56$ & 0.491 \\
\hline$N_{\mathrm{RBC}}\left(10^{6} / \mu \mathrm{L}\right)$ & $4.66 \pm 0.51$ & $4.67 \pm 0.57$ & $4.84 \pm 0.61$ & 0.168 \\
\hline $\mathrm{HbA}_{\mathrm{lc}}(\%)$ & $8.85 \pm 2.49$ & $8.68 \pm 2.38$ & $8.84 \pm 2.49$ & 0.857 \\
\hline$\eta_{\mathrm{PV}}(\mathrm{mPa} \cdot \mathrm{s})$ & $1.37 \pm 0.10$ & $1.40 \pm 0.09^{\star}$ & $1.45 \pm 0.09^{\star \$}$ & $<0.001$ \\
\hline$\eta_{\mathrm{BV}, 1.0}(\mathrm{mPa} \cdot \mathrm{s})$ & $15.94 \pm 2.73$ & $17.15 \pm 2.97^{*}$ & $17.32 \pm 3.07^{\star}$ & 0.020 \\
\hline$\eta_{\mathrm{BV}, 50.0}(\mathrm{mPa} \cdot \mathrm{s})$ & $4.44 \pm 0.63$ & $4.57 \pm 0.60$ & $4.73 \pm 0.68^{\star}$ & 0.064 \\
\hline$\eta_{\mathrm{BV}, 200.0}(\mathrm{mPa} \cdot \mathrm{s})$ & $3.78 \pm 0.53$ & $3.87 \pm 0.49$ & $4.04 \pm 0.58^{* \$}$ & 0.043 \\
\hline $\mathrm{Ai}$ & $4.24 \pm 0.52$ & $4.43 \pm 0.57^{\star}$ & $4.30 \pm 0.53$ & 0.035 \\
\hline $\mathrm{Ri}$ & $4.01 \pm 0.55$ & $3.93 \pm 0.62$ & $3.99 \pm 0.67$ & 0.617 \\
\hline
\end{tabular}

Group A: $C_{F N}<2.5 \mathrm{mg} / \mathrm{dL}$; Group B: $2.5 \mathrm{mg} / \mathrm{dL} \leq C_{F N}<3.5 \mathrm{mg} / \mathrm{dL}$; Group C: $C_{F N} \geq$ $3.5 \mathrm{mg} / \mathrm{dL}$. The selected parameters in this table are defined exactly the same as those in Table 1. ${ }^{*}, P<0.05$, vs. Group A; ${ }^{\$}, P<0.05$, vs. Group B.
Group C, which is in agreement with previous studies that these two variables decreased in the elderly subjects as they grow older (De Meyer et al., 2008; Zierk et al., 2020). It also shows that there are no statistically significant differences in the mean values of $\mathrm{HbA}_{1 \mathrm{c}}, \mathrm{GSP}$, and $\mathrm{RBC} \mathrm{Ri}$. However, different from the results presented above, our results show that the values of

TABLE 3 | Selected biochemical, hematologic and hemorheological characteristics of the T2DM blood subjects by tertile of the whole blood viscosity at low shear rate of $\dot{\gamma}=1.0 \mathrm{~s}^{-1}$.

\begin{tabular}{|c|c|c|c|c|}
\hline \multirow{2}{*}{ Item } & \multicolumn{3}{|c|}{ Subjects } & \multirow{2}{*}{$P$} \\
\hline & Group A & Group B & Group C & \\
\hline $\operatorname{Sex}(M / F)$ & $33 / 46$ & $107 / 61$ & $59 / 12$ & - \\
\hline Age & $63.64 \pm 12.19$ & $56.41 \pm 12.55^{\star}$ & $54.10 \pm 12.55^{\star}$ & $<0.001$ \\
\hline Hct (\%) & $38.66 \pm 3.06$ & $42.90 \pm 3.60^{*}$ & $46.07 \pm 3.68^{\star \$}$ & $<0.001$ \\
\hline MCV (fL) & $92.22 \pm 5.03$ & $90.90 \pm 4.49^{*}$ & $90.17 \pm 5.11^{*}$ & 0.027 \\
\hline$N_{\mathrm{RBC}}\left(10^{6} / \mu \mathrm{L}\right)$ & $4.20 \pm 0.40$ & $4.73 \pm 0.45^{\star}$ & $5.13 \pm 0.56^{\star \$}$ & $<0.001$ \\
\hline$c_{\mathrm{FN}}(\mathrm{mg} / \mathrm{dL})$ & $2.92 \pm 0.71$ & $2.94 \pm 0.53$ & $3.23 \pm 0.58^{\star \$}$ & 0.001 \\
\hline GSP (\%) & $3.01 \pm 0.97$ & $2.90 \pm 0.94$ & $3.07 \pm 0.92$ & 0.434 \\
\hline $\mathrm{HbA}_{1 \mathrm{c}}(\%)$ & $8.94 \pm 2.43$ & $8.70 \pm 2.46$ & $8.57 \pm 2.27$ & 0.621 \\
\hline $\mathrm{HDL}-\mathrm{C}(\mathrm{mmol} / \mathrm{L})$ & $1.18 \pm 0.32$ & $1.22 \pm 0.33$ & $1.16 \pm 0.27$ & 0.445 \\
\hline LDL-C (mmol/L) & $2.90 \pm 0.92$ & $3.16 \pm 0.91$ & $3.23 \pm 0.97$ & 0.060 \\
\hline $\mathrm{TG}(\mathrm{mmol} / \mathrm{L})$ & $1.46 \pm 0.70$ & $1.44 \pm 0.87$ & $1.65 \pm 0.80$ & 0.155 \\
\hline TC (mmol/L) & $4.43 \pm 1.23$ & $4.70 \pm 1.23$ & $4.79 \pm 1.24$ & 0.163 \\
\hline$\eta_{\mathrm{PV}}(\mathrm{mPa} \cdot \mathrm{s})$ & $1.39 \pm 0.09$ & $1.40 \pm 0.10$ & $1.43 \pm 0.09^{\star \$}$ & 0.008 \\
\hline $\mathrm{Ai}$ & $3.88 \pm 0.40$ & $4.42 \pm 0.42^{*}$ & $4.87 \pm 0.54^{\star \$}$ & $<0.001$ \\
\hline Ri & $3.96 \pm 0.64$ & $3.97 \pm 0.57$ & $3.88 \pm 0.69$ & 0.583 \\
\hline$\eta_{\mathrm{rBV}, \text { low }}(\mathrm{mPa} \cdot \mathrm{s})$ & $29.63 \pm 3.00$ & $34.78 \pm 2.80^{\star}$ & $40.36 \pm 4.59^{\star \$}$ & $<0.001$ \\
\hline
\end{tabular}

Group A: $\eta_{B V}, 1.0<15.0 \mathrm{mPa}$; Group B: $15.0 \mathrm{mPa} \cdot \mathrm{S} \leq \eta_{B V}, 1.0<19.0 \mathrm{mPa} \cdot \mathrm{s} ;$ Group C: $\eta_{B V}, 1.0>19.0 \mathrm{mPa}$.s. $H D L-C$, high-density lipoprotein cholesterol; $L D L-C$, low-density

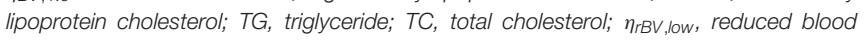
viscosity at low shear rate. Other parameters in this table are defined exactly the same as listed in Tables 1, 2. ${ }^{*}, P<0.05$, vs. Group A; $\$, P<0.05$, vs. Group B.
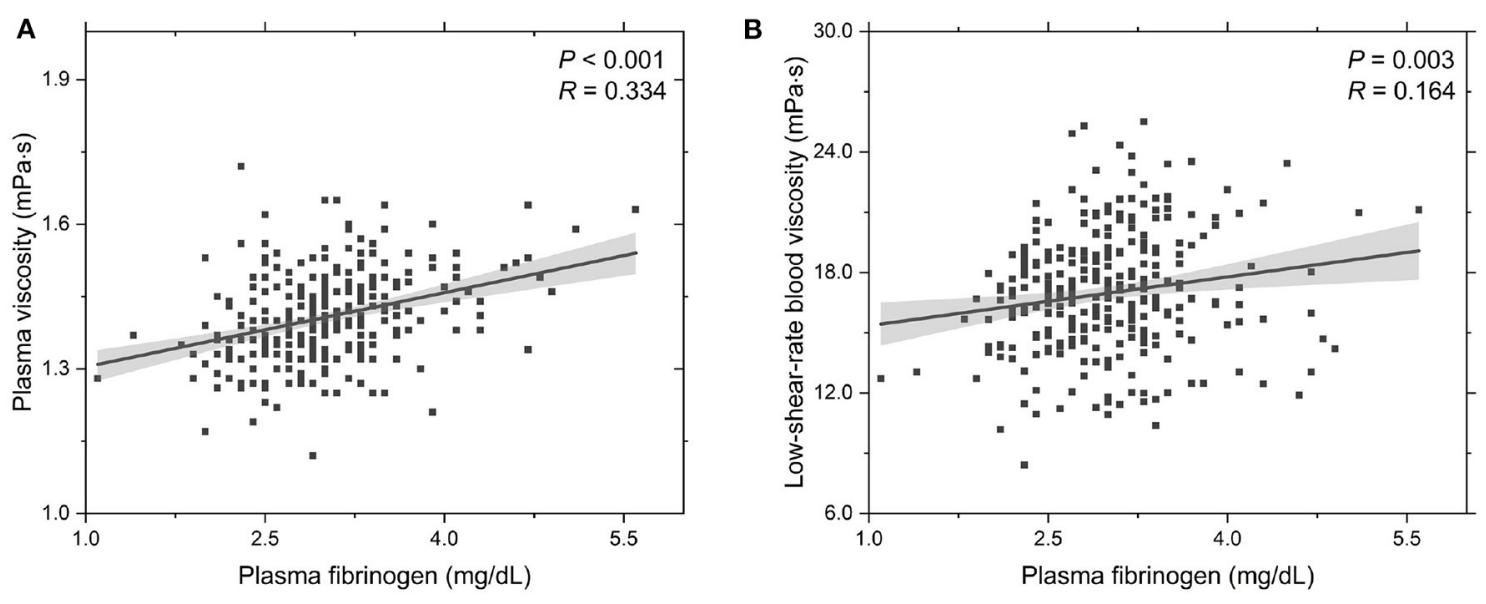

FIGURE 2 | Functional dependencies of (A) plasma viscosity $\eta_{\mathrm{PV}}$ and (B) whole blood viscosity $\eta_{\mathrm{BV}, \text { low }}$ at $\dot{\gamma}=1.0 \mathrm{~s}^{-1}$ with respect to plasma fibrinogen level $C_{\mathrm{FN}}$. Shadow region represents $95 \%$ confidence interval. 


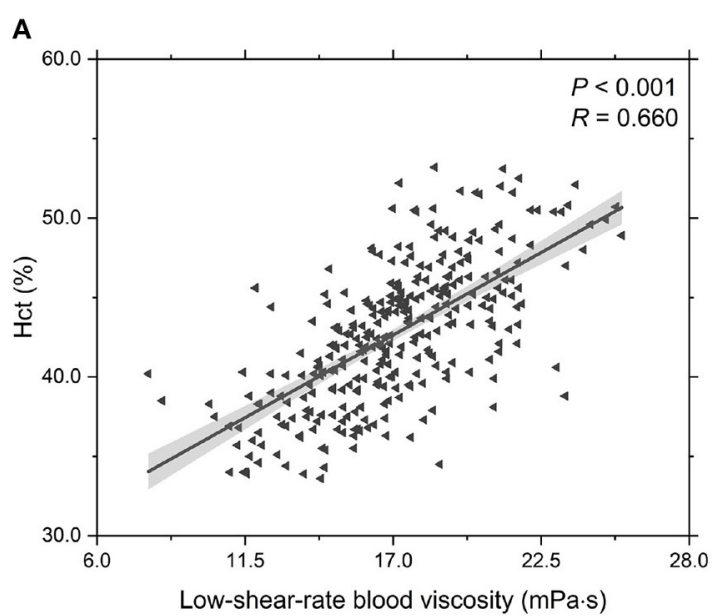

C

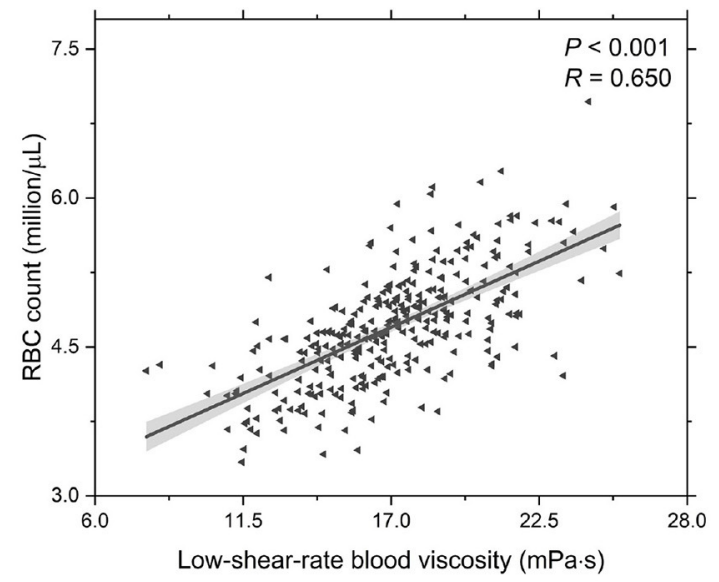

B

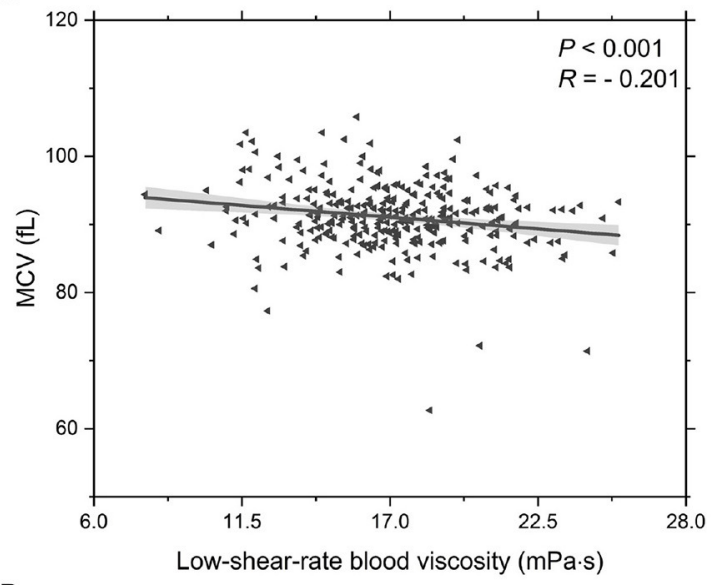

D

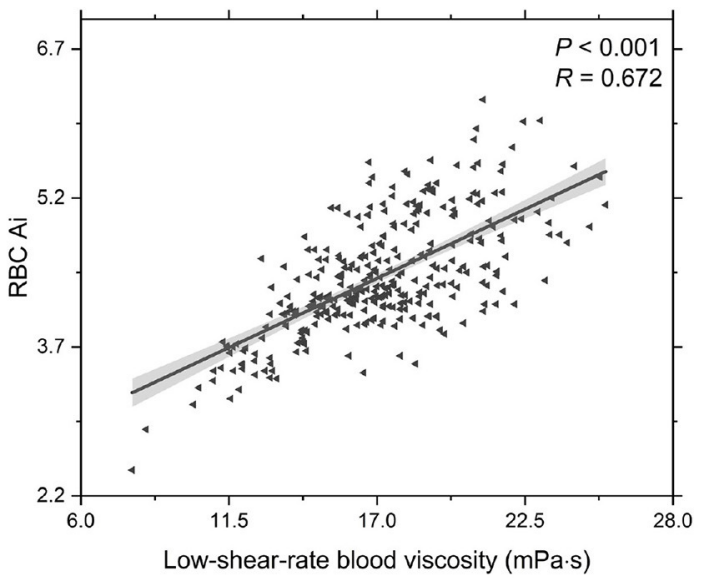

FIGURE 3 | Functional dependencies of (A) Hct, (B) MCV, (C) RBC count, and (D) RBC Ai with respect to low-shear-rate T2DM blood viscosity at $\dot{\gamma}=1.0 \mathrm{~s}^{-1}$. Shadow region represents $95 \%$ confidence interval.

Hct, plasma fibrinogen level $c_{\mathrm{FN}}$, and RBC Ai gradually increase from Group A to Group C. In a previous study by Irace et al. (2014), it has been shown that the plasma viscosity is directly associated with the low-density lipoprotein (LDL) cholesterol. Herein, we also consider the mean values of different cholesterol levels. Our results show that the values of LDL cholesterol were increased from Group A to Group C, resulting in a gradual increase in the plasma viscosity from Group A to Group C. To better understand the alteration of the T2DM blood viscosity in response to the changes in the RBC aggregation induced by the plasma fibrinogen level, we evaluate the reduced blood viscosity at low shear rate $\left(\dot{\gamma}=1.0 \mathrm{~s}^{-1}\right), \eta_{\mathrm{rBV} \text {,low }}$, defined by,

$$
\eta_{\mathrm{rBV}, \mathrm{low}}=\frac{\eta_{\mathrm{BV}, 1.0}-\eta_{\mathrm{PV}}}{\mathrm{Hct}}
$$

From Table 3, we find that the values of $\eta_{\mathrm{rBV}}$, low have a remarkable increase from Group A to Group C, which is mainly due to the enhanced $\mathrm{RBC}$ aggregation ( $\mathrm{RBC} \mathrm{Ai}$ ) induced by the increased level of plasma fibrinogen.
In addition, we investigate the functional dependencies of Hct, MCV, RBC count and RBC Ai on the low-shear-rate blood viscosity, see Figure 3. It shows that the Hct level increases with increasing low-shear-rate blood viscosity (Figure 3A), indicating that the T2DM patients with an abnormal elevation in lowshear-rate blood viscosity have high Hct levels. From the other point of view, it confirms that the Hct level is one of the major determinants of blood viscosity. As we know, the blood hematocrit reflects the amount of space in the blood that is occupied by the RBCs, which are affected by the size of the RBCs (MCV) and by the number of RBCs (RBC counts). The results on the functional dependence of the MCV and $\mathrm{RBC}$ count on the low-shear-rate blood viscosity are shown in (Figures 3B,C). In general, MCV decreases (Figure 3B) while $\mathrm{RBC}$ counts grows (Figure $3 \mathrm{C}$ ) with increasing low-shear-rate blood viscosity, indicating that the increased number of RBCs in the T2BM blood plays a key role in the increased Hct level, causing an elevated low-shear-rate blood viscosity. Additionally, we also probe the functional dependence of RBC Ai on the lowshear-rate blood viscosity (Figure 3D). We find that the RBC Ai 
TABLE 4 | Selected biochemical, hematologic and hemorheological characteristics of the T2DM blood subjects by tertile of the whole blood viscosity at high shear rate of $\dot{\gamma}=200.0 \mathrm{~s}^{-1}$.

\begin{tabular}{|c|c|c|c|c|}
\hline \multirow{2}{*}{ Item } & \multicolumn{3}{|c|}{ Subjects } & \multirow{2}{*}{$P$} \\
\hline & Group A & Group B & Group C & \\
\hline $\operatorname{Sex}(M / F)$ & $46 / 25$ & $117 / 90$ & $36 / 4$ & - \\
\hline Age & $63.15 \pm 12.85$ & $57.18 \pm 12.71^{*}$ & $50.68 \pm 10.03^{\star \$}$ & $<0.001$ \\
\hline Hct (\%) & $38.14 \pm 2.70$ & $43.06 \pm 3.41^{\star}$ & $47.77 \pm 3.62^{\star \$}$ & $<0.001$ \\
\hline MCV (fL) & $92.30 \pm 5.27$ & $90.88 \pm 4.59^{\star}$ & $89.80 \pm 4.73^{\star}$ & 0.021 \\
\hline$N_{\mathrm{RBC}}\left(10^{6} / \mu \mathrm{L}\right)$ & $4.15 \pm 0.38$ & $4.75 \pm 0.46^{\star}$ & $5.34 \pm 0.49^{\star \$}$ & $<0.001$ \\
\hline$C_{\mathrm{FN}}(\mathrm{mg} / \mathrm{dL})$ & $2.91 \pm 0.58$ & $2.97 \pm 0.57$ & $3.29 \pm 0.73^{\star \$}$ & $<0.01$ \\
\hline GSP (\%) & $2.88 \pm 1.03$ & $2.98 \pm 0.92$ & $3.07 \pm 0.91$ & 0.590 \\
\hline $\mathrm{HbA}_{1 \mathrm{c}}(\%)$ & $8.91 \pm 2.48$ & $8.70 \pm 2.42$ & $8.56 \pm 2.25$ & 0.730 \\
\hline HDL-C (mmol/L) & $1.16 \pm 0.27$ & $1.21 \pm 0.34$ & $1.14 \pm 0.28$ & 0.286 \\
\hline LDL-C (mmol/L) & $2.89 \pm 0.92$ & $3.16 \pm 0.91$ & $3.31 \pm 0.99$ & 0.239 \\
\hline TG (mmol/L) & $1.33 \pm 0.67$ & $1.46 \pm 0.78$ & $1.95 \pm 1.05^{\star \$}$ & 0.036 \\
\hline TC (mmol/L) & $4.36 \pm 1.24$ & $4.72 \pm 1.21$ & $4.85 \pm 1.27$ & 0.058 \\
\hline$\eta_{\mathrm{PV}}(\mathrm{mPa} \cdot \mathrm{s})$ & $1.39 \pm 0.10$ & $1.40 \pm 0.09$ & $1.45 \pm 0.09^{* \$}$ & $<0.01$ \\
\hline $\mathrm{Ai}$ & $4.34 \pm 0.70$ & $4.40 \pm 0.52$ & $4.35 \pm 0.49$ & 0.658 \\
\hline Ri & $3.41 \pm 0.52$ & $3.97 \pm 0.47^{\star}$ & $4.67 \pm 0.60^{\star \$}$ & $<0.001$ \\
\hline$\eta_{\mathrm{rBV}, \text { high }}(\mathrm{mPa} \cdot \mathrm{s})$ & $4.70 \pm 0.51$ & $5.56 \pm 0.53^{\star}$ & $6.73 \pm 0.64^{\star \$}$ & $<0.001$ \\
\hline
\end{tabular}

Group A: $\eta_{B V, 200.0}<3.5 \mathrm{mPa}$.s; Group B: $3.5 \mathrm{mPa} \cdot \mathrm{s} \leq \eta_{B V}, 200.0<4.5 \mathrm{mPa} \cdot \mathrm{s}$; Group C: $\eta_{B V}, 200.0 \geq 4.5 \mathrm{mPa} \cdot \mathrm{s} ; \eta_{\mathrm{rBV}}$, high, reduced blood viscosity at high shear rate. Other selected parameters in this table are defined exactly the same as listed in Tables 1-3. *, $P<0.05$, vs. Group $A ;{ }^{\$}, P<0.05$, vs. Group $B$.

is positively associated with the low-shear-rate blood viscosity, indicating that the T2DM patients with higher value of lowshear-rate blood viscosity have enhanced RBC aggregation. Take a look at it another way, we confirm that the RBC aggregation influences the low-shear-rate blood viscosity. In summary, as the values of low-shear-rate blood viscosity are gradually increased from Group A to Group C, we conclude that the T2DM blood viscosity at low shear rate is significantly associated with the increased Hct, plasma viscosity, and RBC aggregation.

At high shear rate $\left(\dot{\gamma}=200.0 \mathrm{~s}^{-1}\right)$, all T2DM blood subjects are also divided into three groups according to their blood viscosity values: Group A $\left(\eta_{\mathrm{BV}, 200.0}<3.5 \mathrm{mPa} \cdot \mathrm{s}\right)$, Group B (3.5 $\left.\mathrm{mPa} \cdot \mathrm{s} \leq \eta_{\mathrm{BV}, 200.0}<4.5 \mathrm{mPa} \cdot \mathrm{s}\right)$, and Group $\mathrm{C}\left(\eta_{\mathrm{BV}, 200.0}>4.5\right.$ $\mathrm{mPa} \cdot \mathrm{s})$. Selected biochemical, hematologic and hemorheological parameters in these three different groups are listed in Table 4. Similar to the trends obtained at low shear rate, it shows that the values of Hct, RBC count, and plasma fibrinogen level $c_{\mathrm{FN}}$ gradually increase from Group A to Group C, and the values of MCV gradually decrease from Group A to Group C. Additionally, our results show that there are no statistically significant differences in the mean values of $\mathrm{HbA}_{1 \mathrm{c}}$ and GSP. In contrast, we find that the values of the RBC Ri gradually increase from Group A to Group C, but the values of the RBC Ai have little changes among the three groups. Next, we evaluate the reduced blood viscosity at high shear rate, $\eta_{\mathrm{rBV}}$,high , defined by,

$$
\eta_{\mathrm{rBV}, \mathrm{high}}=\frac{\eta_{\mathrm{BV}, 200.0}-\eta_{\mathrm{PV}}}{\mathrm{Hct}}
$$

From Table 4, we find that the values of $\eta_{\mathrm{rBV}}$, high gradual increase from Group A to Group C, which could attribute to the increased $\mathrm{RBC} \mathrm{Ri}$, namely the reduced RBC deformability.

In addition, we investigate the functional dependencies of both the RBC Ri and RBC Ai on blood viscosity at high shear rate $\left(\dot{\gamma}=200.0 \mathrm{~s}^{-1}\right)$, see Figure 4 . It shows that the values of the $\mathrm{RBC} \mathrm{Ri}$ are positively correlated with the blood viscosity (Figure 4A); however, there is no correlation between the RBC $\mathrm{Ai}$ and the blood viscosity (Figure 4B). In fact, it is easy to understand because the formation of RBC rouleaux in blood occurs at sufficiently low shear rates. Under high shear stress conditions, the large rouleaux can break down into smaller structures or individual RBCs. Overall, these results confirm that the elevated Hct level and reduced RBC deformability are the two of the most important parameters to the elevated blood viscosity at high shear rate.

\section{SUMMARY}

The viscosity of blood is a direct measure of the resistance of blood to flow, and an increase in blood viscosity would result in retarded blood flow thereby causing reduced delivery of substrates such as oxygen, insulin, and glucose to metabolically active tissues. In this study, we investigate the effects of glycated hemoglobin $\left(\mathrm{HbA}_{1 \mathrm{c}}\right)$ and plasma fibrinogen levels on the rheological properties of blood in subjects with type 2 diabetes mellitus (T2DM). Our data suggest that the mean values of blood viscosity are higher in groups with higher $\mathrm{HbA}_{1 \mathrm{c}}$ levels; however, the correction between the blood viscosity and $\mathrm{HbA}_{1 \mathrm{c}}$ level is not obvious. Instead, we find that the T2DM blood viscosity is significantly and positively correlated with the plasma fibrinogen level.

Additionally, to probe the combined effects of multiple factors (including the $\mathrm{HbA}_{1 \mathrm{c}}$ and plasma fibrinogen levels) on the altered blood viscosity in T2DM subjects, we regroup the experimental data based on the blood viscosity values at both low and high shear rates. Our experimental results suggest that the influence of the elevated $\mathrm{HbA}_{1 \mathrm{c}}$ level on blood viscosity is limited, although it is an important indicator of risk for complications in T2DM patients. Instead, the increased blood hematocrit and enhanced RBC aggregation induced by the elevated plasma fibrinogen level are two of the most important parameters that determine the T2DM blood viscosity at low shear rate, and the increased blood hematocrit and reduced RBC deformation mainly contribute to the elevated T2DM blood viscosity at high shear rate.

Overall, in this study, we show that the RBC aggregation is pronounced while the RBC deformability is decreased in T2DM patients, which may cause blood flow abnormality and eventually lead to the development of vascular complications. On the one hand, the RBC hyperaggregability leads to enhanced rouleau formation at low shear rate, causing blood hyperviscosity in capillaries, reducing the delivery of substrates such as oxygen, insulin and glucose to metobolically active tissues, and eventually leading to hemodynamic impairment and vascular occlusion. On the other hand, the RBCs in patients with T2DM are associated with reduced cell deformation, which can also cause 

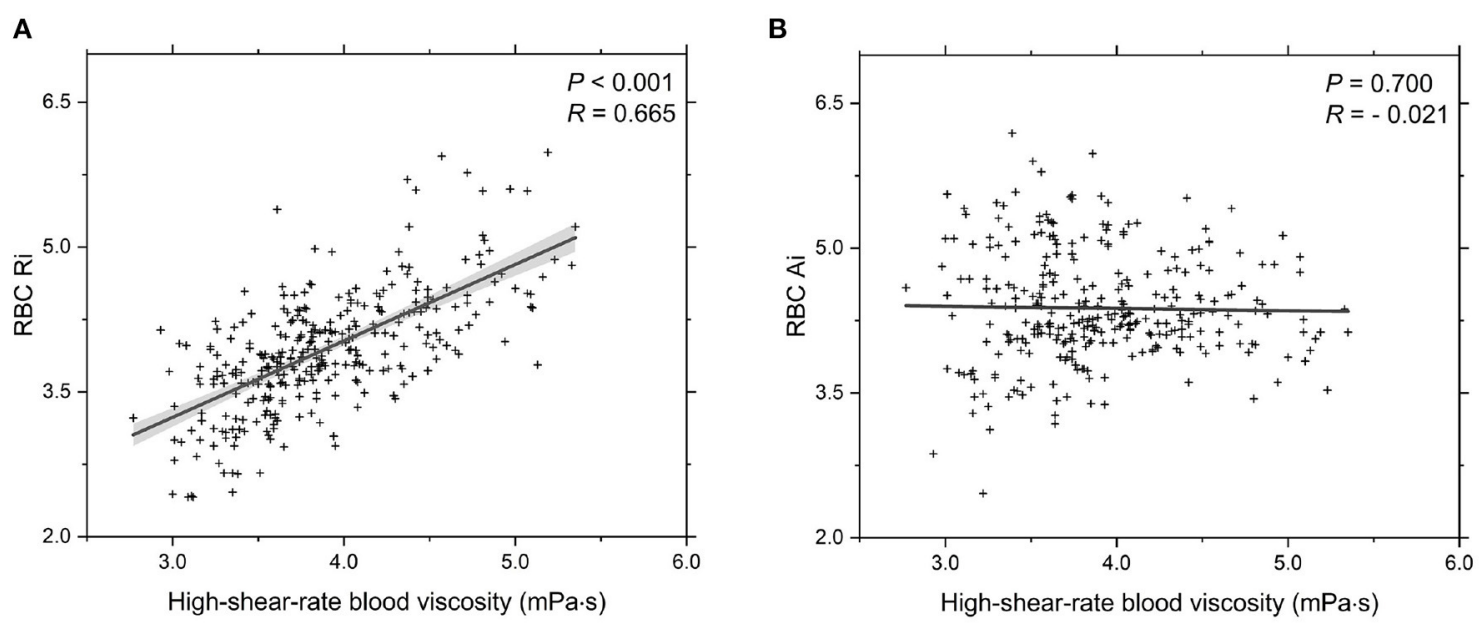

FIGURE 4 | Functional dependencies of (A) RBC Ri and (B) RBC Ai with respect to high-shear-rate T2DM blood viscosity at $\dot{\gamma}=200.0 \mathrm{~s}^{-1}$. Shadow region represents $95 \%$ confidence interval.

blood viscosity elevation contributing to blood flow impairment and other pathophysiological aspects of diabetes-related vascular complications such as the formation of blood clots.

\section{DATA AVAILABILITY STATEMENT}

The original contributions presented in the study are included in the article/supplementary material, further inquiries can be directed to the corresponding authors.

\section{ETHICS STATEMENT}

The studies involving human participants were reviewed and approved by Institutional Review Board (IRB) approvals from the Ningbo First Hospital. Written informed consent for

\section{REFERENCES}

Agrawal R., Smart T., Nobre-Cardoso J., Richards C., Bhatnagar R., Tufail A., et al. (2016). Assessment of red blood cell deformability in type 2 diabetes mellitus and diabetic retinopathy by dual optical tweezers stretching technique. Sci Rep. 6:15873. doi: $10.1038 /$ srep 15873

Babu N., and Singh M. (2004). Influence of hyperglycemia on aggregation, deformability and shape parameters of erythrocytes. Clin. Hemorheol. Micro. 31, 273-280. doi: 10.3233/CH-2009-1165

Bahceci M., Tuzcu A., Ogun C., Canoruc N., Iltimur K., and Aslan C. (2005). Is serum C-reactive protein concentration correlated with HbA1c and insulin resistance in Type 2 diabetic men with or without coronary heart disease? J. Endocrinol. Invest. 28, 145-150. doi: 10.1007/BF033 45357

Ballas S. K., Dover G. J., and Charache S. (1989). Effect of hydroxyurea on the rheological properties of sickle erythrocytes in vivo. Am. J. Hematol. 32, 104-111. doi: 10.1002/ajh.2830320206

Banas A. M., Banas K., Chu T. T. T., Naidu R., Hutchinson P. E., Agrawal R., et al. (2021). Comparing infrared spectroscopic methods for the characterization of Plasmodium falciparum-infected human erythrocytes. Commun. Chem. 4, 129. doi: 10.1038/s42004-021-00567-2 participation was not required for this study in accordance with the national legislation and the institutional requirements.

\section{AUTHOR CONTRIBUTIONS}

JS, KH, MX, JQ, LiL, and XL designed the research. JS and $\mathrm{KH}$ performed the experimental measurements and analyzed the data. All authors discussed the results and wrote this article.

\section{FUNDING}

This work was supported by the Major Program of Social Development of Ningbo Science and Technology Bureau (Grant No. 2019C50094) and the Zhejiang Provincial Natural Science Foundation (Grant No. LY22A020004).
Barshtein G, Ben-Ami R, and Yedgar S. (2007). Role of red blood cell flow behavior in hemodynamics and hemostasis. Exp. Rev. Cardiovasc. Ther. 5, 743-752. doi: 10.1586/14779072.5.4.743

Barshtein G., Arbell D., and Yedgar S. (2018). Hemodynamic functionality of transfused red blood cells in the microcirculation of blood recipients. Front Physiol. 9, 41. doi: 10.3389/fphys.2018.00041

Barshtein G., Goldschmidt N., Pries A. R., Zelig O., Arbell D., and Yedgar S. (2017). Deformability of transfused red blood cells is a potent effector of transfusioninduced hemoglobin increment: a study with beta-thalassemia major patients. Am. J. Hematol. 92, E559-E560. doi: 10.1002/ajh.24821

Barshtein G., Pajic-Lijakovic I., and Gural A. (2021). Deformability of stored red blood cells. Front. Physiol. 12:1497. doi: 10.3389/fphys.2021.722896

Barshtein G., Pries A. R., Goldschmidt N., Zukerman A., Orbach A., Zelig O., et al. (2016). Deformability of transfused red blood cells is a potent determinant of transfusion-induced change in recipient's blood flow. Microcirculation. 23, 479-486. doi: 10.1111/micc.12296

Baskurt O. K., and Meiselman H. J. (2003). Blood rheology and hemodynamics. Semin. Thromb. Hemost. 29, 435-450. doi: 10.1055/s-2003-44551

Beamer N., Giraud G., Clark W., Wynn M., and Coull B. (1997). Diabetes, hypertension and erythrocyte aggregation in acute stroke. Cerebrovasc Dis. 7, 144-149. 
Berger S. A., and King W. (1980). The flow of sickle-cell blood in the capillaries. Biophys J. 29, 119-148. doi: 10.1016/S0006-3495(80)85121-6

Brazionis L., Rowley K., Itsiopoulos C., Harper C. A., and O'Dea K. (2008). Homocysteine and diabetic retinopathy. Diabetes Care. 31, 50-56. doi: $10.2337 / \mathrm{dc} 07-0632$

Brunner E. (2007). "Fibrinogen and clotting factors," in Encyclopedia of Stress (2nd Edition). ed G. Fink (New York, NY: Academic Press), 51-55.

Brust M., Aouane O., Thiébaud M., Flormann D., Verdier C., Kaestner L., et al. (2014). The plasma protein fibrinogen stabilizes clusters of red blood cells in microcapillary flows. Sci. Rep. 4:4348. doi: 10.1038/srep04348

Bull B., Chien S., Dormandy J., Kiesewetter H., Lewis S., Lowe G., et al. (1986). Guidelines for measurement of blood viscosity and erythrocyte deformability. Clin. Hemorheol. Microcirc. 6, 439-453. doi: 10.3233/CH-1986-6510

Chang H. Y., Li X., and Karniadakis G. E. (2017). Modeling of biomechanics and biorheology of red blood cells in type 2 diabetes mellitus. Biophys J. 113, 481-490. doi: 10.1016/j.bpj.2017.06.015

Chang H. Y., Yazdani A., Li X., Douglas K. A., Mantzoros C. S., and Karniadakis G. E. (2018). Quantifying platelet margination in diabetic blood flow. Biophys J. 115, 1371-1382. doi: 10.1016/j.bpj.2018.08.031

Chatterjee S., Khunti K., and Davies M. J. (2017). Type 2 diabetes. Lancet. 389, 2239-2251. doi: 10.1016/S0140-6736(17)30058-2

Chen X. Y., Huang Y. X., Jing L. W., and Jian Y. Z. (2007). Membrane surface charge and morphological and mechanical properties of young and old erythrocytes. Curr. Appl. Phys. 7:e94-e96. doi: 10.1016/j.cap.2006.11.024

Chien S., Usami S., and Bertles J. F., (1970a). Abnormal rheology of oxygenated blood in sickle cell anemia. J. Clin. Invest. 49, 623-634. doi: 10.1172/JCI106273

Chien S., Usami S., Dellenback R., and Gregersen M. (1970b). Shear-dependent interaction of plasma proteins with erythrocytes in blood rheology. Am. Physiol.-Legacy Content. 219, 143-153. doi: 10.1152/ajplegacy.1970.219.1.143

Chien S., Usami S., Dellenback R. J., Gregersen M. I., Nanninga L. B., and Guest M. M. (1967). Blood viscosity: influence of erythrocyte aggregation. Science. 157, 829-831. doi: 10.1126/science.157.3790.829

Chien S., Usami S., Taylor H. M., Lundberg J. L., and Gregersen M. I. (1966). Effects of hematocrit and plasma proteins on human blood rheology at low shear rates. J. Appl. Physiol. 21, 81-87. doi: 10.1152/jappl.1966.21.1.81

Chien W., Gompper G., and Fedosov D. A. (2021). Effect of cytosol viscosity on the flow behavior of red blood cell suspensions in microvessels. Microcirculation. 28:e12668. doi: $10.1111 /$ micc. 12668

Cho H. C. (2011). The relationship among homocysteine, bilirubin, and diabetic retinopathy. Diabetes Metab. J. 35, 595-601. doi: 10.4093/dmj.2011.35.6.595

Cho Y. I., Mooney M. P., and Cho D. J. (2008). Hemorheological disorders in diabetes mellitus. J. Diabetes Sci. Technol. 2, 1130-1138. doi: $10.1177 / 193229680800200622$

Ciuffetti G., Schillaci G., Lombardini R., Pirro M., Vaudo G., and Mannarino E. (2005). Prognostic impact of low-shear whole blood viscosity in hypertensive men. Eur. J. Clin. Invest. 35, 93-98. doi: 10.1111/j.1365-2362.2005.01437.x

Cloutier G., Zimmer A., François T., and Chiasson J. L. (2008). Increased shear rate resistance and fastest kinetics of erythrocyte aggregation in diabetes measured with ultrasound. Diabetes Care. 31, 1400-1402.

Davies M., Brophy S., Williams R., and Taylor A. (2006). The prevalence, severity, and impact of painful diabetic peripheral neuropathy in type 2 diabetes. Diabetes Care. 29, 1518-1522. doi: 10.2337/dc05-2228

De Meyer T., De Buyzere M. L., Langlois M., Rietzschel E. R., Cassiman P., De Bacquer D., et al. (2008). Lower red blood cell counts in middle-aged subjects with shorter peripheral blood leukocyte telomere length. Aging Cell. 7, 700-705. doi: 10.1111/j.1474-9726.2008.00419.x

Dearnley M., Chu T., Zhang Y., Looker O., Huang C., Klonis N., et al. (2016). Reversible host cell remodeling underpins deformability changes in malaria parasite sexual blood stages. Proc. Natl. Acad. Sci. U.S.A. 113, 4800-4805. doi: 10.1073/pnas.1520194113

Deng Y., Lu L., Aponte L., Angelidi A. M., Novak V., Karniadakis G. E., et al. (2021). Deep transfer learning and data augmentation improve glucose levels prediction in type 2 diabetes patients. NPJ Digit. Med. 4:109. doi: 10.1038/s41746-021-00480-x

Deng Y., Papageorgiou D. P., Li X., Perakakis N., Mantzoros C. S., Dao M., et al. (2020). Quantifying fibrinogen-dependent aggregation of red blood cells in Type 2 Diabetes Mellitus. Biophys. J. 119, 900-912. doi: 10.1016/j.bpj.2020.07.026
Dintenfass L. (1985). Red cell rigidity, Tk, and filtration. Clin. Hemorheol. Microcirc. 5, 241-244. doi: 10.3233/CH-1985-5308

Du E., Diez-Silva M., Kato G. J., Dao M., and Suresh S. (2015). Kinetics of sickle cell biorheology and implications for painful vasoocclusive crisis. Proc. Natl. Acad. Sci. U.S.A. 112, 1422-1427. doi: 10.1073/pnas.1424111112

Ercan M., Konukoğlu D., Erdem T., and Önen S. (2002). The effects of cholesterol levels on hemorheological parameters in diabetic patients. Clin. Hemorheol. Microcirc. 26, 257-263.

Fedosov D. A., Caswell B., Suresh S., and Karniadakis G. E. (2011a). Quantifying the biophysical characteristics of plasmodium-falciparum-parasitized red blood cells in microcirculation. Proc. Natl. Acad. Sci. U.S.A. 108, 35-39. doi: $10.1073 /$ pnas. 1009492108

Fedosov D. A., Dao M., Karniadakis G. E., and Suresh S. (2014a). Computational biorheology of human blood flow in health and disease. Ann. Biomed. Eng. 42, 368-387. doi: 10.1007/s10439-013-0922-3

Fedosov D. A., Noguchi H., and Gompper G. (2014b). Multiscale modeling of blood flow: from single cells to blood rheology. Biomech. Model Mechanobiol. 13, 239-258. doi: 10.1007/s10237-013-0497-9

Fedosov D. A., Pan W., Caswell B., Gompper G., and Karniadakis G. E. (2011b). Predicting human blood viscosity in silico. Proc. Natl. Acad. Sci. U.S.A. 108, 11772-11777. doi: 10.1073/pnas.1101210108

Fowler M. J. (2008). Microvascular and macrovascular complications of diabetes. Clin. Diabetes. 26, 77-82. doi: 10.2337/diaclin.26.2.77

Irace C., Carallo C., Scavelli F., and Esposito T. (2014). Influence of blood lipids on plasma and blood viscosity. Clin. Hemorheol. Microcirc. 57, 83-290. doi: 10.3233/CH-131705

Jeganathan V. S. E., Wang J. J., and Wong T. Y. (2008). Ocular associations of diabetes other than diabetic retinopathy. Diabetes Care. 31, 1905-1912. doi: $10.2337 / \mathrm{dc} 08-0342$

Kameneva M., Watach M., and Borovetz H. (1999). Gender difference in rheologic properties of blood and risk of cardiovascular diseases. Clin. Hemorheol. Microcirc. 21, 357-363.

Krüger-Genge A., Sternitzky R., Pindur G., Rampling M., Franke R., and Jung F. (2019). Erythrocyte aggregation in relation to plasma proteins and lipids. J. Cell. Biotechnol. 5, 65-70. doi: 10.3233/JCB-189014

Lapolla A., Poli T., Meneghini F., Zucchetto M., Franchin A., Barison A., et al. (1988). Glycated serum proteins and glucose tolerance. Acta Diabetol Lat. 25, 325-332.

Lei H., and Karniadakis G. E. (2013). Probing vasoocclusion phenomena in sickle cell anemia via mesoscopic simulations. Proc. Natl. Acad. Sci. U.S.A. 110, 11326-11330. doi: 10.1073/pnas.1221297110

Li H., Papageorgiou D. P., Chang H. Y., Lu L., Yang J., and Deng Y. (2018). Synergistic integration of laboratory and numerical approaches in studies of the biomechanics of diseased red blood cells. Biosensors. 8, 76. doi: 10.3390/bios 8030076

Li H., Sampani K., Zheng X., Papageorgiou D. P., Yazdani A., Bernabeu M. O., et al. (2020). Predictive modelling of thrombus formation in diabetic retinal microaneurysms. R. Soc. Open Sci. 7:201102. doi: 10.1098/rsos.201102

MacRury S., Lennie S., McColl P., Balendra R., MacCuish A., and Lowe G. (1993). Increased red cell aggregation in diabetes mellitus: association with cardiovascular risk factors. Diabetic Med. 10, 21-26.

Mathers C. D., and Loncar D. (2006). Projections of global mortality and burden of disease from 2002 to 2030. PLoS Med. 3:e442. doi: 10.1371/journal.pmed.0030442

Matsuda T., and Murakami M. (1976). Relationship between fibrinogen and blood viscosity. Thromb Res. 8, 25-33. doi: 10.1016/0049-3848(76)90044-X

McMillan D. E. (1983). The effect of diabetes on blood flow properties. Diabetes. $32,56-63$

Mokken F. C., Kedaria M., Henny C. P., Hardeman M., and Gelb A. (1992), The clinical importance of erythrocyte deformability, a hemorrheological parameter. Ann. Hematol. 64, 113-122.

Nash G. B., and Meiselman H. J. (1985). Alteration of red cell membrane viscoelasticity by heat treatment: effect on cell deformability and suspension viscosity. Biorheology. 22, 73-84.

Perakakis N., Yazdani A., Karniadakis G. E., and Mantzoros C. (2018). Omics, big data and machine learning as tools to propel understanding of biological mechanisms and to discover novel diagnostics and therapeutics. Metabolism. 87, A1-A9. doi: 10.1016/j.metabol.2018.08.002 
Phillips R., Kondev J., and Theriot J. (2008). Physical Biology of the Cell. New York, NY: Garland Science.

Popel A. S., and Johnson P. C. (2005). Microcirculation and hemorheology. Annu. Rev. Fluid Mech. 37, 43-69. doi: 10.1146/annurev.fluid.37.042604.133933

Sacks D. B. (2011). A1C versus glucose testing: a comparison. Diabetes Care. 34, 518-523. doi: $10.2337 / \mathrm{dc10}-1546$

Schmid-Schönbein H., and Volger E. (1976). Red-cell aggregation and red-cell deformability in diabetes. Diabetes. 25, 897-902. doi: 10.2337/dc07-1802

Secomb T. W. (2017). Blood flow in the microcirculation. Annu. Rev. Fluid Mech. 49, 443-461. doi: 10.1146/annurev-fluid-010816-060302

Shelby J. P., White J., Ganesan K., Rathod P. K., and Chiu D. T. (2003). A microfluidic model for single-cell capillary obstruction by Plasmodium falciparum-infected erythrocytes. Proc. Natl. Acad. Sci. U.S.A. 100, 1461814622. doi: 10.1073/pnas. 2433968100

Skalak R., Keller S. R., and Secomb T. W. (1981). Mechanics of blood flow. J. Biomech. Eng. 103, 102-115.

Skovborg F., Nielsen A., Schlichtkrull J., and Ditzel J. (1966). Blood-viscosity in diabetic patients. Lancet. 287, 129-131.

Sloop G. D. (1996). A unifying theory of atherogenesis. Med. Hypotheses. 47, 321-325. doi: 10.1016/s0306-9877(96)90073-0

Sohrabi S., Wang S., Tan J., Xu J., Yang J., and Liu Y. (2017). Nanoparticle transport and delivery in a heterogeneous pulmonary vasculature. J Biomech. 50, 240-247. doi: 10.1016/j.jbiomech.2016.11.023

Spengler M., Svetaz M., Leroux M., Bertoluzzo S., Carrara P., Van Isseldyk F., et al. (2011). Erythrocyte aggregation in patients with systemic lupus erythematosus. Clin. Hemorheol. Microcirc. 47, 279-285. doi: 10.20944/preprints201907.0090.v1

Stamos T. D., and Rosenson R. S. (1999). Low high density lipoprotein levels are associated with an elevated blood viscosity. Atherosclerosis. 146, 161-165.

Tamariz L. J., Young J. H., Pankow J. S., Yeh H. C., Schmidt M. I., Astor B., et al. (2008). Blood viscosity and hematocrit as risk factors for type 2 diabetes mellitus: the atherosclerosis risk in communities (ARIC) study. Am. J. Epidemiol. 168, 1153-1160.

Tan J., Sohrabi S., He R., and Liu Y. (2018). Numerical simulation of cell squeezing through a micropore by the immersed boundary method. Proc. Inst. Mech. Eng. C J. Mec Eng. Sci. 232, 502-514. doi: 10.1177/0954411918764508

Tomaiuolo G., Carciati A., Caserta S., and Guido S. (2016). Blood linear viscoelasticity by small amplitude oscillatory flow. Rheol Acta. 55, 485-495. doi: 10.1007/s00397-015-0894-3

Turczynski B., Michalska-Malecka K., Slowinska L., Szczesny S., and Romaniuk W. (2003). Correlations between the severity of retinopathy in diabetic patients and whole blood and plasma viscosity. Clin. Hemorheol. Microcirc. 29, 129-137.

Wesołowski A., and Młynarczak A. (2019). Surface tension and viscosity of blood. Preprint. doi: 10.20944/preprints2019070090v1
Xiao L. L., Lin C. S., Chen S., Liu Y., Fu B. M., and Yan W. W. (2020). Effects of red blood cell aggregation on the blood flow in a symmetrical stenosed microvessel. Biomech. Model Mechanobiol. 19, 159-171. doi: 10.1007/s10237-019-01202-9

Yang H., Sloan G., Ye Y., Wang S., Duan B., Tesfaye S., et al. (2020). New perspective in diabetic neuropathy: from the periphery to the brain, a call for early detection, and precision medicine. Front Endocrinol. 10, 929. doi: 10.3389/fendo.2019.00929

Yao C., Huang Y., Li X., and Ruan P. (2003). Effects of pH on structure and function of single living erythrocyte. Chin. Sci. Bull. 48, 1342-1346. doi: 10.1007/BF03184176

Yazdani A., Deng Y., Li H., Javadi E., Li Z., Jamali S., et al. (2021). Integrating blood cell mechanics, platelet adhesive dynamics and coagulation cascade for modeling thrombus formation in normal and diabetic blood. J. R. Soc. Interface. 18:20200834. doi: 10.1098/rsif.2020.0834

Yedgar S, Koshkaryev A, and Barshtein G. (2002). The red blood cell in vascular occlusion. Pathophysiol. Haemostasis. Thromb. 32, 263-268. doi: $10.1159 / 000073578$

Young M., Boulton A., MacLeod A., Williams D., and Sonksen P. (1993). A multicentre study of the prevalence of diabetic peripheral neuropathy in the United Kingdom hospital clinic population. Diabetologia. 36, 150-154.

Zhang Y., Huang C., Kim S., Golkaram M., Dixon M. W. A., Tilley L., et al. (2015). Multiple stiffening effects of nanoscale knobs on human red blood cells infected with Plasmodium falciparum malaria parasite. Proc. Natl. Acad. Sci. U.S.A. 112, 6068-6073. doi: 10.1073/pnas.1505584112

Zierk J., Krebs A., Rauh M., Metzler M., Loscher A., Strasser E., et al. (2020). Blood counts in adult and elderly individuals: defining the norms over eight decades of life. Br. J. Haematol. 189, 777-789. doi: 10.1111/bjh.16430

Conflict of Interest: The authors declare that the research was conducted in the absence of any commercial or financial relationships that could be construed as a potential conflict of interest.

Publisher's Note: All claims expressed in this article are solely those of the authors and do not necessarily represent those of their affiliated organizations, or those of the publisher, the editors and the reviewers. Any product that may be evaluated in this article, or claim that may be made by its manufacturer, is not guaranteed or endorsed by the publisher.

Copyright $\odot 2022$ Sun, Han, Xu, Li, Qian, Li and Li. This is an open-access article distributed under the terms of the Creative Commons Attribution License (CC BY). The use, distribution or reproduction in other forums is permitted, provided the original author(s) and the copyright owner(s) are credited and that the original publication in this journal is cited, in accordance with accepted academic practice. No use, distribution or reproduction is permitted which does not comply with these terms. 